\title{
Isoniazid as a substrate and inhibitor of myeloperoxidase: Identification of amine adducts and the influence of superoxide dismutase on their formation
}

\author{
Louisa V. Forbes $^{\mathrm{a}, *}$, Paul G. Furtmüller ${ }^{\mathrm{b}}$, Irada Khalilova ${ }^{\mathrm{a}}$, Rufus Turner ${ }^{\mathrm{a}}$, Christian Obinger ${ }^{\mathrm{b}}$, \\ Anthony J. Kettle ${ }^{\mathrm{a}}$ \\ ${ }^{a}$ Centre for Free Radical Research, Department of Pathology, University of Otago Christchurch, P.O. Box 4345, Christchurch, New Zealand \\ ${ }^{\mathrm{b}}$ Department of Chemistry, Division of Biochemistry, VIBT - Vienna Institute of BioTechnology, BOKU-University of Natural Resources and Life Sciences, Vienna, Austria
}

\section{A R T I C L E I N F O}

\section{Article history:}

Received 1 May 2012

Accepted 18 July 2012

Available online 27 July 2012

\section{Keywords:}

Isoniazid

Myeloperoxidase

Neutrophils

Superoxide dismutase

Oxidation

\begin{abstract}
A B S T R A C T
Neutrophils ingest Mycobacteria tuberculosis (Mtb) in the lungs of infected individuals. During phagocytosis they use myeloperoxidase (MPO) to catalyze production of hypochlorous acid ( $\mathrm{HOCl})$, their most potent antimicrobial agent. Isoniazid ( $\mathrm{INH}$ ), the foremost antibiotic in the treatment of tuberculosis, is oxidized by MPO. It rapidly reduced compound I of MPO $\left[k=(1.22 \pm 0.05) \times 10^{6} \mathrm{M}^{-1} \mathrm{~s}^{-1}\right]$ but reacted less favorably with compound II $\left[(9.8 \pm 0.6) \times 10^{2} \mathrm{M}^{-1} \mathrm{~s}^{-1}\right]$. Oxidation of INH by MPO and hydrogen peroxide was unaffected by chloride, the physiological substrate for compound I, and the enzyme was partially converted to compound III. This indicates that INH is oxidized outside the classical peroxidation cycle. In combination with superoxide dismutase (SOD), MPO oxidized INH without exogenous hydrogen peroxide. SOD must favor reduction of oxygen by the INH radical to give superoxide and ultimately hydrogen peroxide. In both oxidation systems, an adduct with methionine was formed and it was a major product with MPO and SOD. We show that it is a conjugate of an acyldiimide with amines. INH substantially inhibited $\mathrm{HOCl}$ production by MPO and neutrophils below pharmacological concentrations. The reversible inhibition is explained by diversion of MPO to its ferrous and compound III forms during oxidation of INH. MPO, along with SOD released by $M t b$, will oxidize INH at sites of infection and their interactions are likely to limit the efficacy of the drug, promote adverse drug reactions via formation of protein adducts, and impair a major bacterial killing mechanism of neutrophils.
\end{abstract}

(c) 2012 Elsevier Inc. All rights reserved.

\section{Introduction}

Isonicotinic acid hydrazide, or isoniazid (INH), remains an important drug in the fight against tuberculosis 60 years after its discovery [1,2]. Resistance of Mycobacterium tuberculosis (Mtb) to $\mathrm{INH}$, however, is an increasing clinical problem in the management of this disease worldwide [3]. Given that $30 \%$ of the world's population is infected with Mtb and 10 million new cases occur annually, it is critically important to fully understand the molecular and cellular basis of the action of INH. INH is a prodrug that undergoes oxidation in $M t b$ by a catalase-peroxidase, KatG [4]. Mutations in KatG that make Mtb resistant to INH blunt superoxide-dependent oxidation of INH but have little impact on peroxide-dependent oxidation [5]. These findings suggest that KatG uses superoxide to oxidize INH within $M t b$.

Recently it was shown that neutrophils play a dominant role in phagocytosis of $M t b$ in the lungs of infected individuals [6]. This finding has important implications for the efficacy of INH because

\footnotetext{
* Corresponding author. Tel.: +6433640590.

E-mail address: louisa.forbes@otago.ac.nz (L.V. Forbes).
}

neutrophils contain an abundance of myeloperoxidase (MPO), which oxidizes INH in a similar fashion to KatG $[7,8]$. The normal function of MPO is to promote oxidative killing of bacteria trapped within phagosomes of neutrophils. This heme enzyme uses hydrogen peroxide and superoxide to oxidize chloride to hypochlorous acid ( $\mathrm{HOCl}$ ) [9]. The interplay between MPO and INH is of interest because it may limit the ability of the drug and/or neutrophils to kill Mtb. For example, oxidation of INH by MPO may deplete its local concentrations as well as inhibit the production of $\mathrm{HOCl}$. Oxidation of INH by MPO may also contribute to its idiosyncratic effects $[7,10]$. Mtb releases large amounts of SOD $[11,12]$ and at sites of infection this enzyme is also likely to affect interactions between MPO, INH and superoxide. An additional bonus is that an understanding of the mechanism of oxidation of INH by MPO could provide new insights into how it may be oxidized by KatG within Mtb.

MPO undergoes enzymatic cycling via its redox intermediates compounds I and II [13]. When hydrogen peroxide reacts with the ferric native enzyme, it produces highly reactive compound I, which has a two-electron reduction potential of $1.16 \mathrm{~V}$ [14]. This enables it to oxidize chloride, bromide and thiocyanate and cycle back to its native form. Compound I also undergoes one-electron 
reduction by substrates to form compound II and a substrate radical. Compound II is then reduced back to the native enzyme and forms another substrate radical. Physiological substrates include urate, ascorbate, tyrosine and superoxide [13,15]. The single-electron reduction potential of compound I is $1.36 \mathrm{~V}$ compared to $0.97 \mathrm{~V}$ for compound II [16] making the reduction of compound II the rate determining step in enzyme turnover. These reduction potentials are higher than the corresponding values for other peroxidases and give MPO a more diverse substrate preference. An additional intermediate, compound III or oxymyeloperoxidase, is generated by reaction of the ferric enzyme with superoxide, or via one-electron reduction of the native enzyme to its ferrous state with subsequent binding of oxygen $[13,17,18]$. Compound III is less reactive than the other redox intermediates of MPO but is reduced by ascorbate, superoxide and serotonin [19-21].

Pharmacological doses of INH cause peak plasma and intrapulmonary concentrations of approximately $30 \mu \mathrm{M}$ [22-24]. Hence, it is conceivable that INH and MPO will interact in vivo. Previously, activated neutrophils were found to metabolize INH to a product that exhibited in vitro cytotoxicity raising concerns for idiosyncratic drug reactions $[7,25]$. To date, it remains unclear how effective INH is as a substrate for MPO compared to physiological substrates and whether it affects the ability of neutrophils to produce $\mathrm{HOCl}$. Therefore, we have addressed these shortcomings to fully appreciate how the interactions of INH and MPO influence both the pharmacology of this important drug and its impact on a major arm of innate immunity.

\section{Materials and methods}

\subsection{Materials}

Human MPO was purchased from Planta Natural Products (Austria). Its concentration per heme was determined by measuring its absorbance at $430 \mathrm{~nm}\left(\varepsilon_{430}=89,000 \mathrm{M}^{-1} \mathrm{~cm}^{-1}\right)$ [26] and its purity index, $A_{430} / A_{280}$ was at least 0.82 . Hydrogen peroxide $\left(\mathrm{H}_{2} \mathrm{O}_{2}\right.$, $30 \%$ solution) was supplied by LabServ, or from Sigma-Aldrich (Austria). It was diluted fresh each day and its concentration determined by measuring its absorbance at $240 \mathrm{~nm}$ $\left(\varepsilon_{240}=43.6 \mathrm{l} \mathrm{M}^{-1} \mathrm{~cm}^{-1}\right)$ [27]. INH, isonicotinic acid, isonicotinamide, methionine and lysine compounds, taurine, diethylenetriamine penta-acetic acid, tetramethylbenzidine, phorbyl myristate acetate, superoxide dismutase (from bovine erythrocytes), catalase (from bovine liver), and Extra-avidin alkaline phosphatase were all from Sigma-Aldrich (USA). 4-Aminobenzoic acid hydrazide $(\mathrm{ABAH})$ was from Fluka Chemicals (Germany). For isolation of neutrophils, Ficoll-Paque (GE Healthcare, Sweden) and dextran from Leuconostoc mesenteroides (ave. mol. wt. 150,000, SigmaAldrich) were used. The immobilized MPO assay used the following antibodies: mouse monoclonal antibody to human MPO from Abcam (UK), goat anti-rabbit biotinylated antibody from Dako (Denmark) and rabbit polyclonal anti-human MPO (produced inhouse). Reagent Amplex Ultra-Red was from Invitrogen (USA), $p$ nitrophenyl phosphate disodium salt was from Strem Chemicals (USA), and 96-wells flat bottom high binding polystyrene plates were from Costar (USA). All buffer salts were analytical grade and solvents were chromatography grade.

\subsection{Transient state experiments}

The stopped-flow apparatus (model SX-18MV) equipped for both conventional and sequential stopped-flow measurements was from Applied Photophysics (UK). For a total of $100 \mu \mathrm{L} / \mathrm{shot}$ into the optical observation cell with $1 \mathrm{~cm}$ light path, the fastest time for mixing two solutions and recording the first data point was of the order of $1.2 \mathrm{~ms}$. All measurements were performed at $25{ }^{\circ} \mathrm{C}$. Due to the inherent instability of MPO compound I, the sequential stopped-flow (multi-mixing) technique was used for determination of rates of the reaction of compound I with INH. Typically, MPO $(4 \mu \mathrm{M})$ was premixed with $\mathrm{H}_{2} \mathrm{O}_{2}(40 \mu \mathrm{M})$ in the aging loop for $40 \mathrm{~ms}$ in $100 \mathrm{mM}$ phosphate buffer, $\mathrm{pH}$ 7.0. Compound I was then allowed to react with varying concentrations of INH. Formation of compound II was followed at $456 \mathrm{~nm}$. At least three determinations were performed for each INH concentration. The mean of the pseudo-first-order rate constants, $k_{\mathrm{obs}}$, was used in the calculation of the second-order rate constants obtained from the slope of a plot of $k_{\text {obs }}$ against INH concentrations.

Reactivity of compound II was investigated by starting with preformed compound II which subsequently reacted with INH causing an exponential decrease in absorbance at $456 \mathrm{~nm}$. In a typical experiment, MPO $(4 \mu \mathrm{M})$ was premixed with a 10 -fold concentration of $\mathrm{H}_{2} \mathrm{O}_{2}$ and equimolar homovanillic acid (that reduces compound I but cannot donate electrons to compound II) in $100 \mathrm{mM}$ phosphate buffer, $\mathrm{pH}$ 7.0. After a delay time of $40 \mathrm{~s}$, compound II was allowed to react with varying concentrations of INH in the same buffer.

\subsection{HPLC and MS analysis of INH oxidation products}

A reverse phase gradient separation was carried out at room temperature on a Waters Alliance 2690 high pressure liquid chromatography (HPLC) system using a Phenomenex Gemini-NX $3 \mu \mathrm{m} \mathrm{C18}$ column $(150 \mathrm{~mm} \times 2 \mathrm{~mm})$. Solvent A was $20 \mathrm{mM}$ ammonium acetate buffer ( $\mathrm{pH}$ 6.9) and solvent B was $100 \%$ methanol. Standards or reaction samples $(50 \mu \mathrm{L})$ were injected using an autosampler. After an initial $5 \mathrm{~min}$ of $0 \% \mathrm{~B}$, there were consecutive linear gradients of $0-40 \%$ B over $10 \mathrm{~min}, 40-75 \%$ B over $1 \mathrm{~min}$ with $75 \% \mathrm{~B}$ maintained for another minute, followed by a return to $0 \%$ B over $1 \mathrm{~min}$, then $0 \%$ B for a further $7 \mathrm{~min}$. A flow rate of $200 \mu \mathrm{L} / \mathrm{min}$ was used throughout the $25 \mathrm{~min}$ run. Monitoring the absorbance at $262 \mathrm{~nm}$ with an online Waters 996 photodiode array detector allowed detection of INH and its derivatives. Quantitation by peak area was done using standard curves for INH, isonicotinic acid and isonicotinamide which were linear from 0 to $200 \mu \mathrm{M}$. Chromeleon software, version 6.80 (Dionex, USA), was used to test eluted peak purity using two parameters; the peak assymetry measurement standard of European Pharmcopeia (EP), and the peak purity index (PPI). EP values between 1.2 and 5.0 are considered to be of acceptable purity for quantification, and a low percentage relative standard deviation of the PPI (RSD PPI) indicates low deviation from a theoretically pure peak.

Identification of eluted isoniazid oxidation products was confirmed by mass spectrometry (MS). Electrospray ionization MS analysis was performed using a Thermo LCQ Deca Ion Trap (San Jose, CA) coupled to a Thermo Surveyor HPLC (LCMS) using identical gradient conditions as above, with the column held at $25^{\circ} \mathrm{C}$. For the first $4 \mathrm{~min}$, negative ionization was performed for identification of isonicotinic acid. After $4 \mathrm{~min}$, the mode was switched to positive ionization. The electrospray was held at $5 \mathrm{kV}$, nitrogen (the sheath gas), was set at 38 (arbitrary units) throughout the run and the capillary temperature was $280^{\circ} \mathrm{C}$. The fragmentation of isoniazid adducts was performed by $\mathrm{MS}^{n}$ experiments with collision energy at $28-35 \%$, and product ions monitored from 50 to $300 \mathrm{~m} / \mathrm{z}$.

\subsection{Spectrophotometric analysis of heme changes in MPO}

Visible absorbance spectra were recorded on an Agilent 7500 diode array spectrophotometer operated at room temperature. Spectra between 190 and $1100 \mathrm{~nm}$ ( $1 \mathrm{~nm}$ intervals) were recorded 
every $30 \mathrm{~s}$ for kinetic studies. Each spectrum was the average of 10 readings taken over $1 \mathrm{~s}$. Experiments were performed a minimum of three times. Prior to analysis of reactions between MPO and INH, spectra were blanked against INH and, where appropriate, against catalase. Reactions were typically carried out in a final volume of $500 \mu \mathrm{L}$ in a quartz cuvette with $1 \mathrm{~cm}$ light path, with reagents added in minimal volume (usually 1-5\% final) and mixed within $5 \mathrm{~s}$. Recorded spectra were corrected to overlay the baselines at $800 \mathrm{~nm}$.

\subsection{Activity assays for MPO}

\subsubsection{Taurine chloramine assay in neutrophils and an isolated MPO-} $\mathrm{H}_{2} \mathrm{O}_{2}$ system

The chlorination activity of MPO was determined by measuring the production of $\mathrm{HOCl}$ which was trapped as taurine chloramine. For the $\mathrm{MPO}-\mathrm{H}_{2} \mathrm{O}_{2}$ system, reaction mixtures contained $20 \mathrm{nM}$ MPO, $5 \mathrm{mM}$ taurine, and various concentrations of INH in phosphate buffered saline (PBS; $10 \mathrm{mM}$ sodium/potassium phosphate in $137 \mathrm{mM} \mathrm{NaCl}$ and $2.7 \mathrm{mM} \mathrm{KCl}, \mathrm{pH} 7.4$ ). Reactions were carried out at room temperature $\left(21^{\circ} \mathrm{C}\right)$, started by adding $50 \mu \mathrm{M}$ $\mathrm{H}_{2} \mathrm{O}_{2}$ and stopped after $4-8 \mathrm{~min}$ by adding $20 \mu \mathrm{g} / \mathrm{mL}$ catalase. The reaction time was chosen so that no more than $50 \%$ of the $\mathrm{H}_{2} \mathrm{O}_{2}$ was converted to $\mathrm{HOCl}$. The trapping of $\mathrm{HOCl}$ as taurine chloramine was assayed using the iodide-catalyzed oxidation of 3,3',5,5'-tetramethylbenzidine (TMB) [28]. For cell experiments, human neutrophils were prepared by dextran sedimentation followed by Ficoll-Paque centrifugation and hypotonic lysis of contaminating erythrocytes from freshly drawn heparinized-blood of healthy volunteers [29]. Neutrophils $\left(2 \times 10^{6} / \mathrm{mL}\right)$ were stimulated with $100 \mathrm{ng} / \mathrm{mL}$ phorbol 12-myristate 13-acetate (PMA) in Hanks balanced salt solution (PBS with $0.5 \mathrm{mM}$ magnesium chloride, $1 \mathrm{mM}$ calcium chloride and $5.5 \mathrm{mM}$ glucose), also containing $5 \mathrm{mM}$ taurine and various concentrations of INH. Reactions were performed at $37{ }^{\circ} \mathrm{C}$ and stopped after $20 \mathrm{~min}$ by adding $20 \mu \mathrm{g} /$ $\mathrm{mL}$ catalase and placing tubes in melting ice. Cells were pelleted by centrifugation $(10,000 \times g, 3 \mathrm{~min})$ and the accumulated taurine chloramine was measured in the supernatant as described above. Single function exponential curves were fitted to the doseresponse data using non-linear regression (SigmaPlot, Jandel Scientific, USA).

\subsubsection{Peroxidation assay}

The oxidation of TMB in the absence of halides was used to determine the peroxidase activity of MPO. This was used as a measure of residual activity of the enzyme following prior reaction with inhibitor. Initially, MPO (150 nM) was incubated with $50 \mu \mathrm{M}$ INH or ABAH and reactions started by adding $50 \mu \mathrm{M} \mathrm{H}_{2} \mathrm{O}_{2}$. After 30 min reaction mixtures were then diluted 200 -fold into $200 \mathrm{mM}$ acetate buffer, $\mathrm{pH} 5.4$, containing $10 \%(\mathrm{v} / \mathrm{v})$ dimethylformamide and a fresh solution of TMB and $\mathrm{H}_{2} \mathrm{O}_{2}$ added to give final concentrations of $2 \mathrm{mM}$ and $200 \mu \mathrm{M}$ respectively. The absorbance of oxidized TMB $(650 \mathrm{~nm})$ was measured after $10 \mathrm{~min}$. Reactions were carried out at room temperature and absorbances measured in a Wallac Victor ${ }^{3}$ platereader (Perkin Elmer, Singapore).

\subsubsection{Activity and protein quantitation of immobilized $M P O$}

To measure irreversible inhibition, the activity of MPO after incubation with inhibitor was measured as a proportion of its protein concentration using an enzyme linked immunosorbant assay (ELISA) [30]. Initially, MPO (150 nM) was incubated for 15 min with either INH $(1 \mathrm{mM})$ or ABAH $(1 \mathrm{mM})$ plus concentrations of $\mathrm{H}_{2} \mathrm{O}_{2}$ that ranged from 0 to $100 \mu \mathrm{M}$. Reaction mixtures were then diluted 200-fold for the ELISA. Briefly, plates were coated with a mouse monoclonal antibody to human MPO which captured MPO from samples applied in the assay buffer (PBS with
1\% BSA and $0.025 \%$ Tween-20). After washing, the peroxidase activity was measured first, by adding Amplex Ultra-Red $(50 \mu \mathrm{M})$, in $50 \mathrm{mM}$ phosphate buffer, $\mathrm{pH} 7.4$, containing $20 \mu \mathrm{M} \mathrm{H}_{2} \mathrm{O}_{2}$ and $50 \mathrm{mM}$ sodium bromide. Production of the fluorescent Amplex Ultra-Red oxidation product was measured using $\lambda_{\text {ex }} 544 \mathrm{~nm}$ and $\lambda_{\text {em }} 590 \mathrm{~nm}$. The plate was washed and then subjected to quantification of the captured MPO protein. For this a primary polyclonal rabbit anti-human MPO antibody was followed by a goat anti-rabbit biotinylated secondary antibody, followed by Extra-avidin alkaline phosphatase. Finally, the absorbance of the yellow chromophore from the applied substrate $p$-nitrophenyl phosphate disodium salt was measured at $405 \mathrm{~nm}$. Both the activity and protein measurements were determined using standard curves from 0 to $680 \mathrm{pM}$ of purified MPO.

\section{Results}

\subsection{Reduction of MPO compounds I and II by INH}

To establish how effective INH is as a substrate for compounds I and II of MPO, we measured the rate constants for these reactions using stopped-flow spectrophotometry. Measurements of the MPO transient-state kinetics were made by sequential-mixing stoppedflow experiments. Compound I of MPO was rapidly converted to compound II by INH as indicated by a shift of the Soret band from $430 \mathrm{~nm}$ to $456 \mathrm{~nm}$ with isosbestic points at 433, 494, 574 and $660 \mathrm{~nm}$ (Fig. 1A). Additionally, a small maximum appeared at around $630 \mathrm{~nm}$. The monophasic time traces at $456 \mathrm{~nm}$ were fitted to a single-exponential function (Fig. 1B). The apparent bimolecular rate constant of the reaction between INH and compound I of $(1.22 \pm 0.05) \times 10^{6} \mathrm{M}^{-1} \mathrm{~s}^{-1}\left(\mathrm{pH} 7.0,25^{\circ} \mathrm{C}\right)$ was obtained from the slope of the pseudo-first order rate constants plotted against INH concentration (Fig. 1C).

By contrast, compound II of MPO reacted very slowly with INH. Direct conversion of preformed compound II to the native ferric enzyme occurred with an isosbestic point at $442 \mathrm{~nm}$ (Fig. 2A). During the slow conversion from compound II to the ferric enzyme, the small maximum at $630 \mathrm{~nm}$ shifted to $625 \mathrm{~nm}$ which was indicative of partial compound III formation [31]. Measurement of the decrease in absorbance at $456 \mathrm{~nm}$ (Fig. 2B) gave an apparent bimolecular rate constant of $(9.8 \pm 0.6) \times 10^{2} \mathrm{M}^{-1} \mathrm{~s}^{-1}(\mathrm{pH} 7.0$, $25^{\circ} \mathrm{C}$ ) (Fig. 2C). The formation of some compound III, during the time scale for reduction of compound II, most likely explains the negative intercept observed in Fig. $2 \mathrm{C}$ because it also absorbs at $456 \mathrm{~nm}$. These rate constants indicate that $\mathrm{INH}$ is an effective substrate for compound I but a relatively poor substrate for compound II.

\subsection{Analysis of the oxidation products of INH}

To better understand the mechanism by which MPO oxidizes $\mathrm{INH}$, we identified the products formed in the reaction and how they are influenced by SOD. Methionine was included in reaction mixtures to scavenge any $\mathrm{HOCl}$ formed by MPO when chloride was present. Diethylenetriaminepentaacetic acid (DTPA) was also included to chelate any metal cations that may otherwise catalyze auto-oxidation of INH [5,32]. Incubation of INH with MPO (or hydrogen peroxide alone, not shown) did not lead to oxidation products observable above background by HPLC (Fig. 3A). However, upon addition of MPO and hydrogen peroxide (Fig. 3B) three products were formed. Two of them co-eluted with authentic standards of isonicotinic acid (INA) or isonicotinamide (INAM) (Fig. 3D). They also had the appropriate masses as determined by mass spectrometry (result not shown). Isonicotinic acid was the major oxidation product with reagent hydrogen peroxide. Addition of SOD to MPO and INH promoted the formation of the same three products without the requirement for exogenous hydrogen 

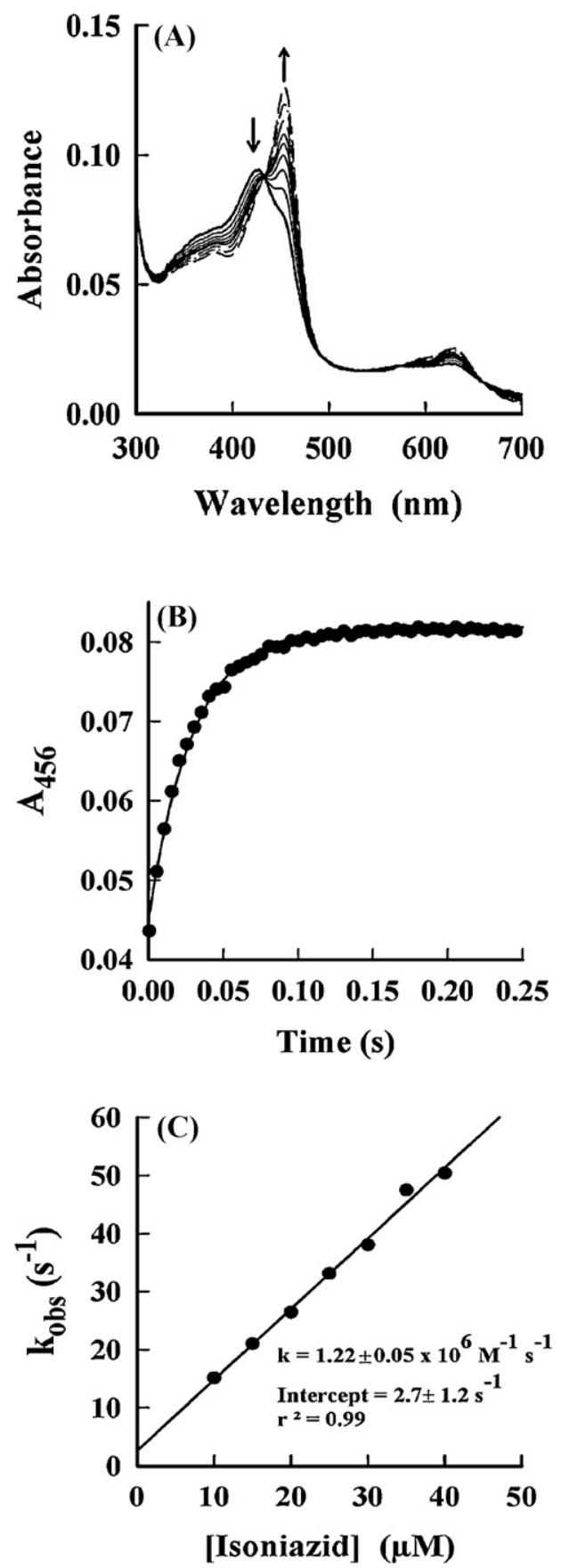

Fig. 1. Reduction of MPO compound I by INH. Experiments were carried out in

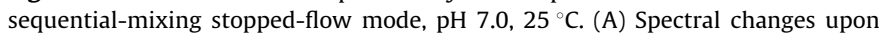
addition of $50 \mu \mathrm{M}$ INH to $4 \mu \mathrm{M}$ compound I. The first spectrum was recorded at $1.3 \mathrm{~ms}$, subsequent spectra at 3.8, 6.4, 9.0, 11.5, 14.1, 19.2, 29.4, and $75 \mathrm{~ms}$. Arrows indicate absorbance changes. (B) A typical time trace of absorbance at $456 \mathrm{~nm}$ for the reaction between $1 \mu \mathrm{M}$ compound I and $25 \mu \mathrm{M}$ INH. (C) Plot of the pseudo-firstorder rate constants of compound I reduction giving a second-order rate constant (slope).

peroxide (Fig. 3C). With SOD the major products were INA and the late eluting peak (approximately $16.5 \mathrm{~min}$ ). SOD alone did not oxidize INH (not shown). The photodiode array spectra observed across the eluted peaks showed uniform profiles typical of the pyridine chromophore with adsorption maxima at $262 \mathrm{~nm}(248-$ $267 \mathrm{~nm}$ range). The EP (and RSD PPI) values for peak purity, see Section 2.3, were $1.30(0.99 \%), 1.40(0.13 \%), 1.45(3.21 \%)$ and 3.63 (1.85\%) for Fig. 3C peaks INA, INH, INAM and Met.A respectively. These values indicate acceptable purity.
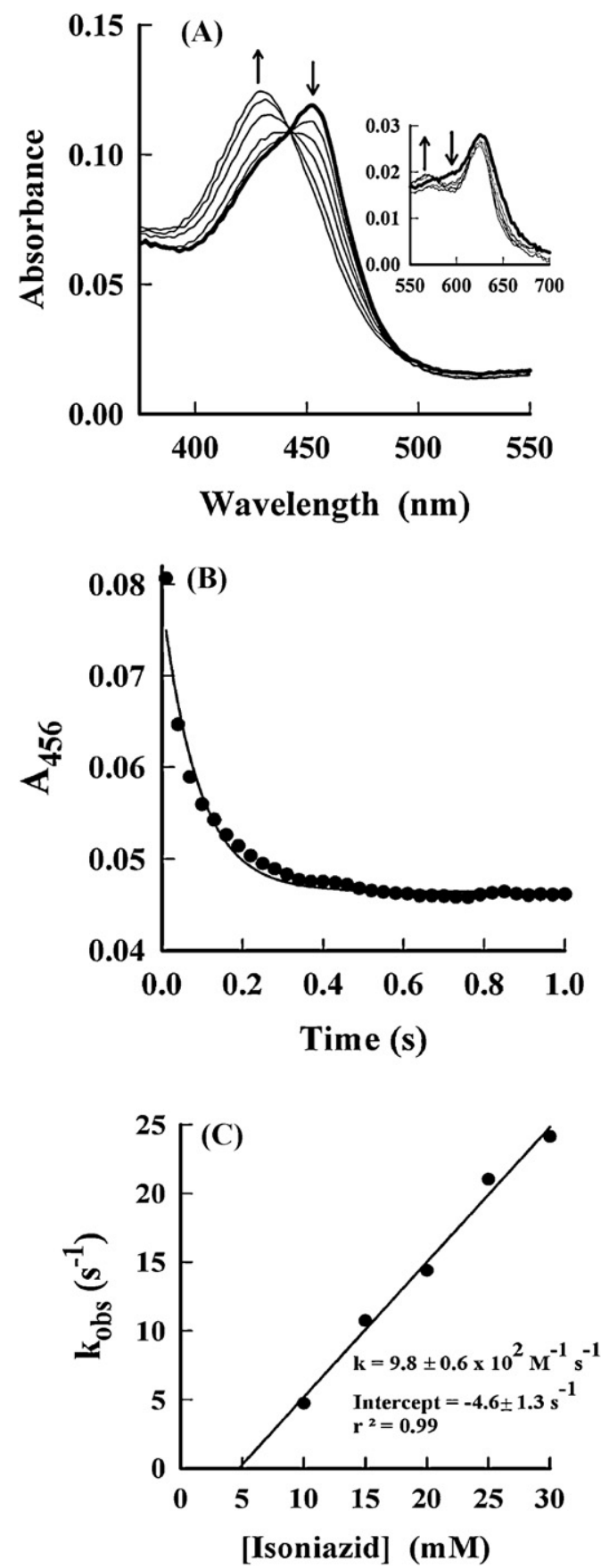

Fig. 2. Reduction of MPO compound II by INH. Experiments were carried out in sequential-mixing stopped-flow mode, $\mathrm{pH} 7.0,25^{\circ} \mathrm{C}$. (A) Spectral changes upon addition of $5 \mathrm{mM}$ INH to $4 \mu \mathrm{M}$ compound II. The first spectrum was recorded at $1 \mathrm{~s}$ (compound II), subsequent spectra were recorded at 1.6, 1.9, 2.2, 2.5 and 6.7 s. (B) A typical time trace $(456 \mathrm{~nm})$ of the reaction between $1 \mu \mathrm{M}$ compound II and $15 \mathrm{mM}$ INH. (C) Plot of the pseudo-first-order rate constants of compound II reduction giving a second-order rate constant (slope).

The product with the longest retention time (approximately $16.5 \mathrm{~min}$ ) had a $m / z$ ratio of 255 and major fragments of 209 and $161 \mathrm{~m} / z$ (Fig. 3E). When the fragments with $\mathrm{m} / z$ values of 209 and 207 were subjected to further fragmentation $\left(\mathrm{MS}^{3}\right)$, they both gave rise to a molecular ion with a $m / z$ value of 161 . This fragmentation pattern is consistent with the product being an adduct between methionine and the isonicotinic acyl group of INH (Fig. 3E inset). The adduct was not formed in the absence of methionine (not shown). Related adducts were also formed 

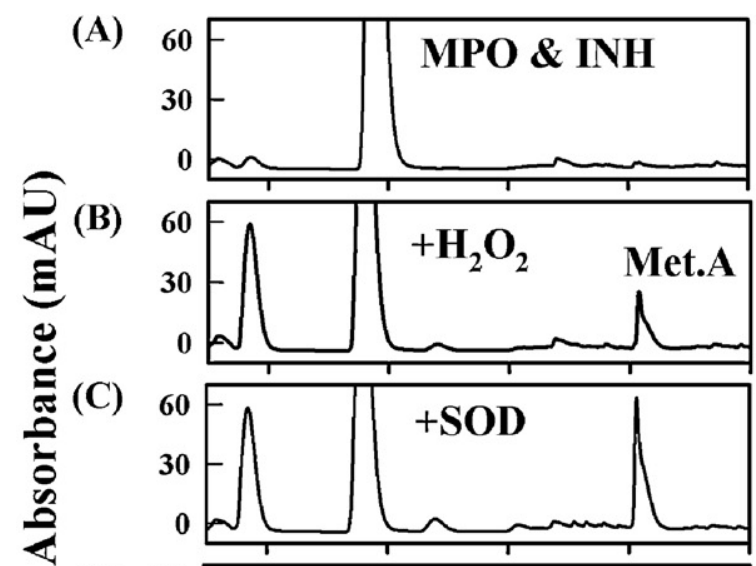

(D)
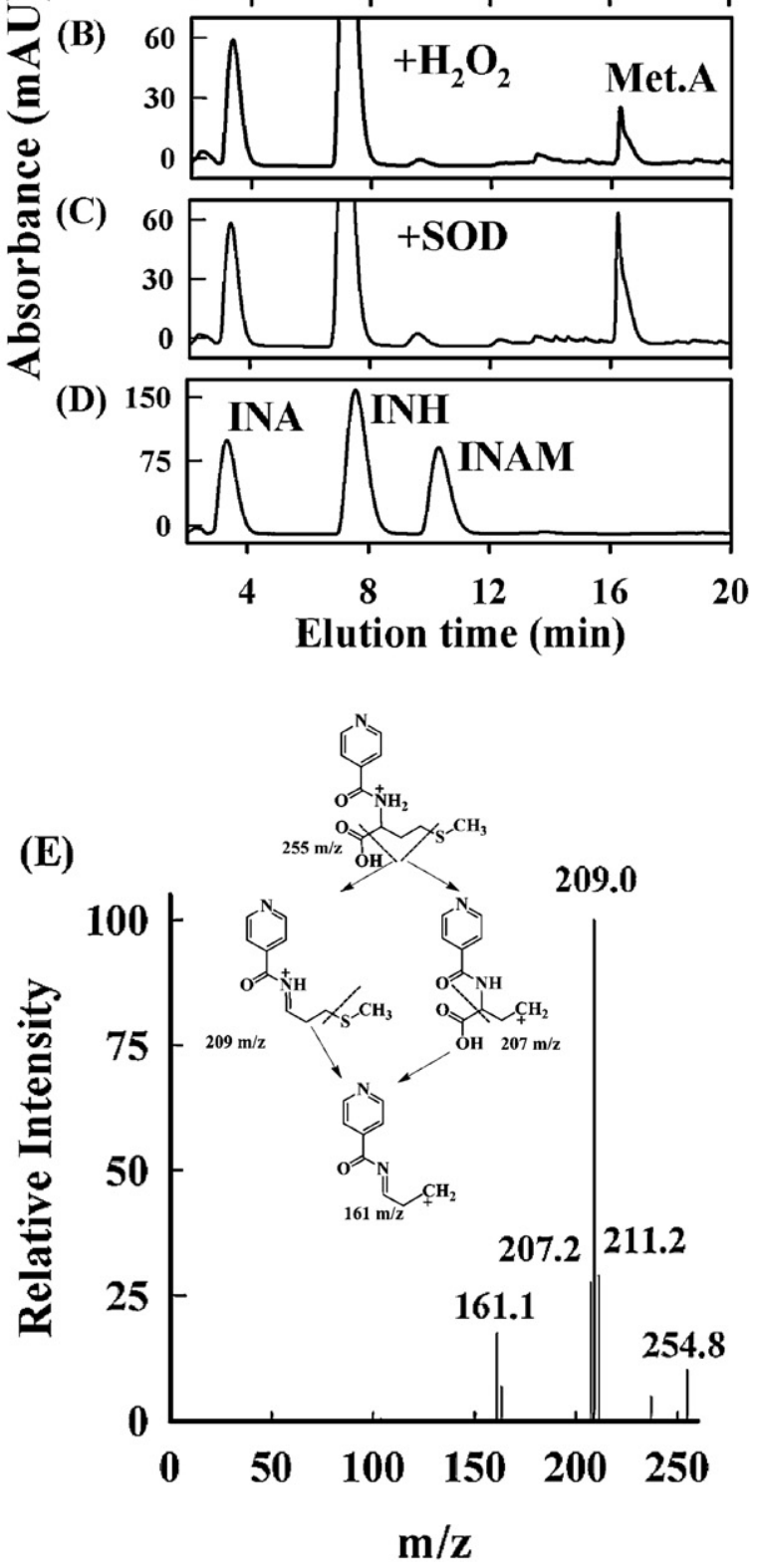

Fig. 3. Detection of INH oxidation products by HPLC and mass spectrometry. Typical chromatograms (262 nm) of room temperature incubations of (A) $200 \mathrm{nM}$ MPO and $200 \mu \mathrm{M}$ INH in $10 \mathrm{mM}$ phosphate buffer $\mathrm{pH} 7.4,100 \mu \mathrm{M}$ DTPA and $1 \mathrm{mM}$ methionine, (B) the same after $2 \mathrm{~h}$ with $100 \mu \mathrm{M} \mathrm{H}_{2} \mathrm{O}_{2}$ or (C) after $2 \mathrm{~h}$ with $40 \mu \mathrm{g} / \mathrm{mL}$ SOD. (D) A mixture of standards containing $100 \mu \mathrm{M}$ each of INH, isonicotinic acid (INA) and isonicatinamide (INAM). (E) MS/MS analysis of the Met.A peak, with proposed structures of fragmentation products (inset).

when methionine sulfoxide or N-acetyl lysine were included in the reaction instead of methionine (Table 1 ). No adduct was formed with $\mathrm{N}$-formyl methionine, nor with $\mathrm{N}$-acetyl cysteine (not shown). These results confirm that the amine group of these amino acids is required for formation of the adducts. In each case the product had a $m / z$ ratio and fragments consistent with the formation of an adduct between the amino acid and the isonicotinic acyl group of INH (Table 1).
When reagent hydrogen peroxide $(25 \mu \mathrm{M})$ was added to MPO $(200 \mathrm{nM})$ and INH $(200 \mu \mathrm{M})$, there was a slow oxidation of INH that was complete within approximately $30 \mathrm{~min}$ (Fig. 4A). There were corresponding increases in INA and the methionine adduct. INAM remained a minor product. As the concentration of hydrogen peroxide was increased in the reaction, there was an increase in the extent of oxidation of INH to a maximum (Fig. 4B). At low concentrations of hydrogen peroxide $(10 \mu \mathrm{M})$ there was superstoichiometric oxidation of INH but at higher concentrations a maximum of approximately $60 \mu \mathrm{M}$ INH was oxidized. INA accounted for $65-80 \%$ of the oxidized INH and INAM no more than $5 \%$. Assuming no other major products were produced, the methionine adduct would have accounted for $15-30 \%$ of oxidized INH. These data suggest that although hydrogen peroxide is required for MPO to oxidize $\mathrm{INH}$, at higher concentrations it must also inhibit the reaction. Addition of SOD to MPO and INH promoted a slow continuous linear oxidation of INH over 3 h even though no exogenous hydrogen peroxide was added (Fig. 4C). INA and INAM accounted for $49 \%$ and $6 \%$ of the oxidized INH, with the remaining $45 \%$ attributed to the methionine adduct.

Chloride, the substrate for compound, I had no effect on hydrogen peroxide dependent oxidation of INH. However, it completely prevented oxidation of INH by MPO and SOD (Fig. 5A). Catalase partially inhibited oxidation of INH by MPO and SOD (Fig. 5B). This result demonstrated that hydrogen peroxide must be produced during the oxidation of INH by MPO and SOD, and that it is required to maintain further oxidation of $\mathrm{INH}$.

\subsection{Spectral analysis of MPO during oxidation of INH}

The redox transformations of MPO were studied during oxidation of INH using standard spectrophotometry to gain further insights into the mechanisms of oxidation. Incubation of MPO with INH alone displayed an unchanged native ferric MPO heme spectrum with its Soret peak at $428 \mathrm{~nm}$ and a minor visible peak at $570 \mathrm{~nm}$ (Fig. 6A). Upon addition of hydrogen peroxide, MPO was converted to compound II within $15 \mathrm{~s}$ as evident by the shift in the Soret peak from $428 \mathrm{~nm}$ to $456 \mathrm{~nm}$ with the concomitant loss in the peak at $570 \mathrm{~nm}$ and the appearance of a broad peak at $630 \mathrm{~nm}$ [31]. By 10 min the compound II peak at $456 \mathrm{~nm}$ had declined with a shoulder appearing at approximately $430 \mathrm{~nm}$. There was also a shift of the peak at longer wavelengths to a sharper peak at $625 \mathrm{~nm}$. These changes are indicative of conversion of the enzyme to a mixture of native enzyme, compounds II and III [31]. In the presence of physiological levels of chloride (Fig. 6B), there was a smaller transformation away from the native ferric state to compound II. This indicated that chloride was competing effectively with INH and limiting its reaction with compound I.

To understand the pathway of conversion of compound II to compound III when MPO oxidizes INH, preformed compound II (gray trace) was reacted with INH (Fig. 6C). Addition of INH to compound II resulted in a broadened Soret peak at $430 \mathrm{~nm}$ and a pronounced peak at $625 \mathrm{~nm}$. This spectrum formed within 1 min of adding INH and was stable. It indicates the presence of ferric enzyme and compound III. Without addition of INH, compound II gradually reverted to the native ferric state with a minor amount left after 7 min as evident from the small peak at $625 \mathrm{~nm}$ (dashed black trace). From these results obtained over a time scale of minutes, and the sub-second observations made in the stoppedflow experiments (Fig. 2), we conclude that when compound II reacts with INH it is initially reduced to ferric MPO, which is then converted to compound III. The latter reaction does not involve INH directly because in the absence of hydrogen peroxide, INH did not affect the spectrum of native enzyme. Thus, an intermediate formed during the oxidation of INH must react with the ferric enzyme to form compound III. 
Table 1

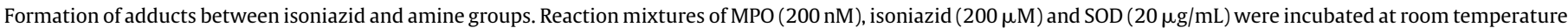

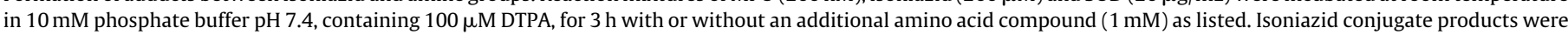

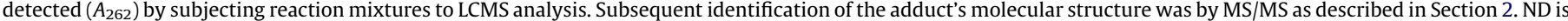
not detected.

\begin{tabular}{|c|c|c|c|c|c|}
\hline \multirow[t]{2}{*}{ Compound $\left([\mathrm{M}+\mathrm{H}]^{+} m / z\right)$} & \multicolumn{5}{|c|}{ LCMS of isoniazid conjugate } \\
\hline & Molecular structure & $\mathrm{RT}(\mathrm{min})$ & $A_{262}$ & {$[\mathrm{M}+\mathrm{H}]^{+} \mathrm{m} / \mathrm{z}$} & MS/MS fragments $m / z$ \\
\hline Isoniazid (alone) (138) & $\mathrm{O} \smile \mathrm{NHNH}_{3}$ & 4.7 & Yes & 138 & 121.0 \\
\hline +L-Methionine (150) & & 17.4 & Yes & 255 & $\begin{array}{l}207.2 \\
\mathbf{2 0 9 . 0} \\
211.2 \\
161.1\end{array}$ \\
\hline +Methionine-DL-sulfoxide (166) & $\mathbf{O H}$ & $7.8,9.3$ & Yes & 271 & 207.2 \\
\hline +N- $\varepsilon$-acetyl-L-lysine (189) & $\mathbf{H}_{3}$ & 15.7 & Yes & 294 & $\begin{array}{l}\mathbf{1 8 9 . 1} \\
248.0 \\
252.2 \\
\mathbf{2 7 6 . 1}\end{array}$ \\
\hline +N-formyl-L-methionine (178) & - & ND & No & - & - \\
\hline
\end{tabular}

Bold type in MS/MS column denotes major fragments.

Compound III is formed either by reaction of ferric enzyme with superoxide or one-electron reduction of ferric enzyme to ferrous MPO followed by rapid binding of oxygen [13]. To determine which pathway was responsible for compound III formation during oxidation of INH, we added SOD to the reaction system. Even in the absence of hydrogen peroxide, MPO was converted almost completely to compound III (Fig. 7A). This indicates that superoxide was not responsible for forming compound III because SOD was present and would scavenge this radical. Addition of catalase to MPO, INH and SOD decreased the rate and extent of conversion of MPO to compound III (Fig. 7B). This shows that hydrogen peroxide is formed in this system and is required to promote conversion of the enzyme to compound III. These data suggest that compound III is formed by reduction of ferric MPO to ferrous MPO with subsequent binding of oxygen, as occurs with substrates 4 -amino benzoic acid hydrazide (ABAH) [33], and hydroquinone [34].

\subsection{The effect of INH on the halogenation activity of MPO}

The production of $\mathrm{HOCl}$ by either a MPO-hydrogen peroxide system or PMA-stimulated human neutrophils was measured by trapping it with taurine and detecting accumulated taurine chloramine [28]. INH was very effective at slowing the production of $\mathrm{HOCl}$ by purified MPO (Fig. 8A). It inhibited the rate of its production by $50 \%\left(\mathrm{IC}_{50}\right)$ at a concentration of $2.7 \mu \mathrm{M}$. The 1000 -fold difference in rate constants for reduction of compounds I and II by INH suggests that INH could inhibit MPO by promoting the accumulation of compound II. However, inhibition of the production of $\mathrm{HOCl}$ was only marginally affected by tyrosine ( $\mathrm{IC}_{50} 4.1 \mu \mathrm{M}$ ). Tyrosine is a good substrate for compound II and prevents its accumulation [35]. It has previously been shown to reverse inhibition of hypochlorous acid production by inhibitors that trap the enzyme in its compound II form [36,37]. Based on the modest effect of tyrosine on inhibition of MPO by INH, we conclude that INH is unlikely to act solely by converting the enzyme to compound II.

INH was also a good inhibitor of $\mathrm{HOCl}$ production by neutrophils having an $\mathrm{IC}_{50}$ of $7.5 \mu \mathrm{M}$ (Fig. 8B). SOD, added to remove superoxide, marginally improved the potency of inhibition ( $\left.\mathrm{IC}_{50} 3.7 \mu \mathrm{M}\right)$. INH $(20 \mu \mathrm{M})$ did not affect production of superoxide by neutrophils nor did it prevent $\mathrm{HOCl}$ from reacting with taurine. Similarly, neither isonicotinic acid nor isonicotinamide inhibited MPO in the taurine chloramine assay at a concentration of $20 \mu \mathrm{M}$ (results not shown). Consequently, we conclude that INH must inhibit production of hypochlorous acid by interacting directly with MPO.

\subsection{Reversibility of MPO inhibition by INH}

Previously, it was demonstrated that $\mathrm{ABAH}$, a structural analog of INH, irreversibly inactivates MPO by destroying the heme prosthetic groups of the enzyme $[33,38]$. Therefore we investigated 

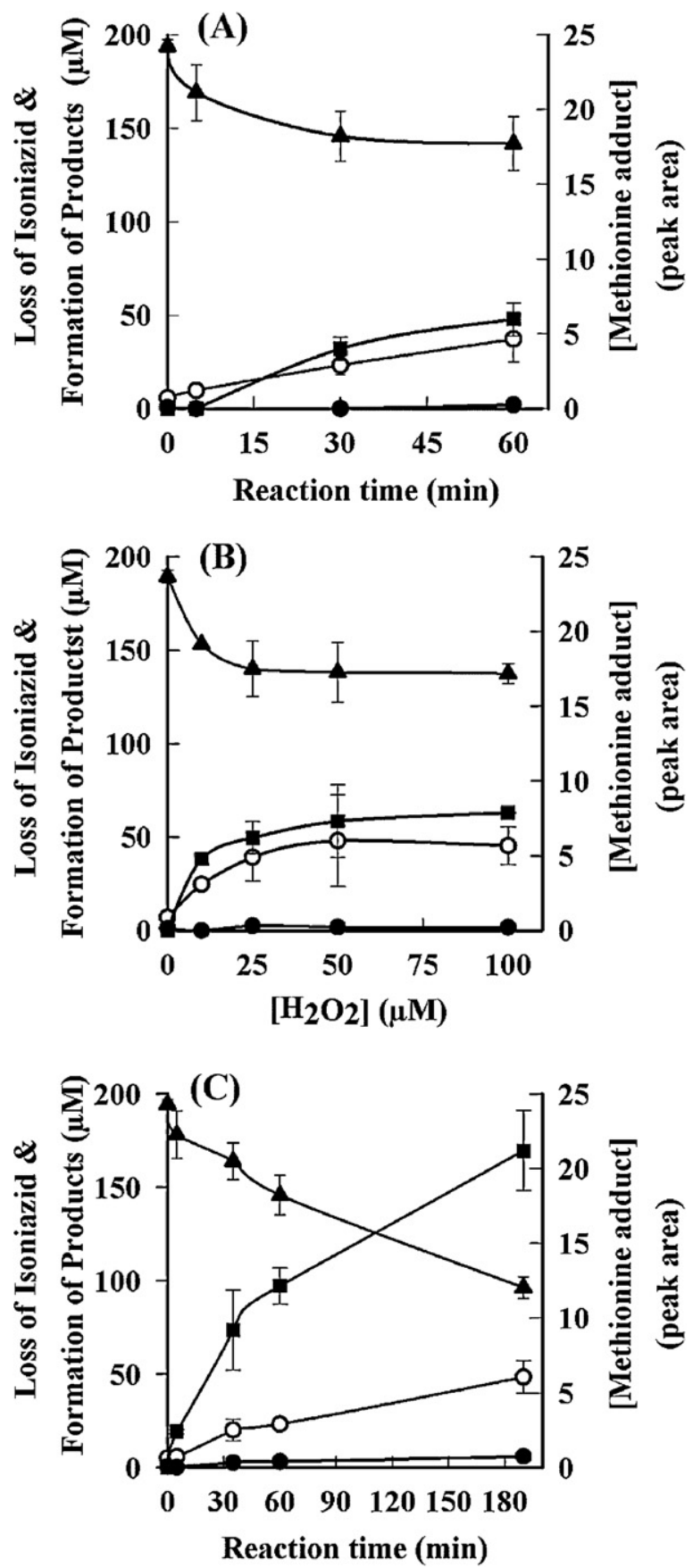

Fig. 4. Oxidation of INH by MPO in the presence of $\mathrm{H}_{2} \mathrm{O}_{2}$ or SOD. The loss of INH ( $\boldsymbol{\Delta}$ ) and formation of oxidation products (INA $\bigcirc$, INAM $\bullet$, Met.A $\boldsymbol{\square}$ ) was monitored upon incubation of $200 \mathrm{nM}$ MPO, $200 \mu \mathrm{M}$ INH in $10 \mathrm{mM}$ phosphate buffer pH 7.4 containing $100 \mu \mathrm{M}$ DTPA and $1 \mathrm{mM}$ methionine, with (A) $25 \mu \mathrm{M} \mathrm{H}_{2} \mathrm{O}_{2}$, (B) with varied $\mathrm{H}_{2} \mathrm{O}_{2}$ concentration for $1 \mathrm{~h}$, and (C) with $40 \mu \mathrm{g} / \mathrm{mL}$ SOD. All data shown are the means from two to four experiments, error bars are standard deviations (SD).

whether INH acts in a similar manner to ABAH. MPO was initially incubated with hydrogen peroxide in the absence or presence of INH. It was then diluted 200 -fold, to effectively remove any ambient inhibitor, and the residual peroxidase activity was measured. Incubation of MPO with hydrogen peroxide alone caused a decrease in the activity of MPO (Fig. 9A). The presence of $\mathrm{INH}$, however, had no additional effect on the residual activity of MPO. In contrast, but consistent with previous results [33], ABAH caused a $90 \%$ loss in enzyme activity.

The effect of INH on the specific activity of MPO was also measured using an activity ELISA. After incubating MPO with INH
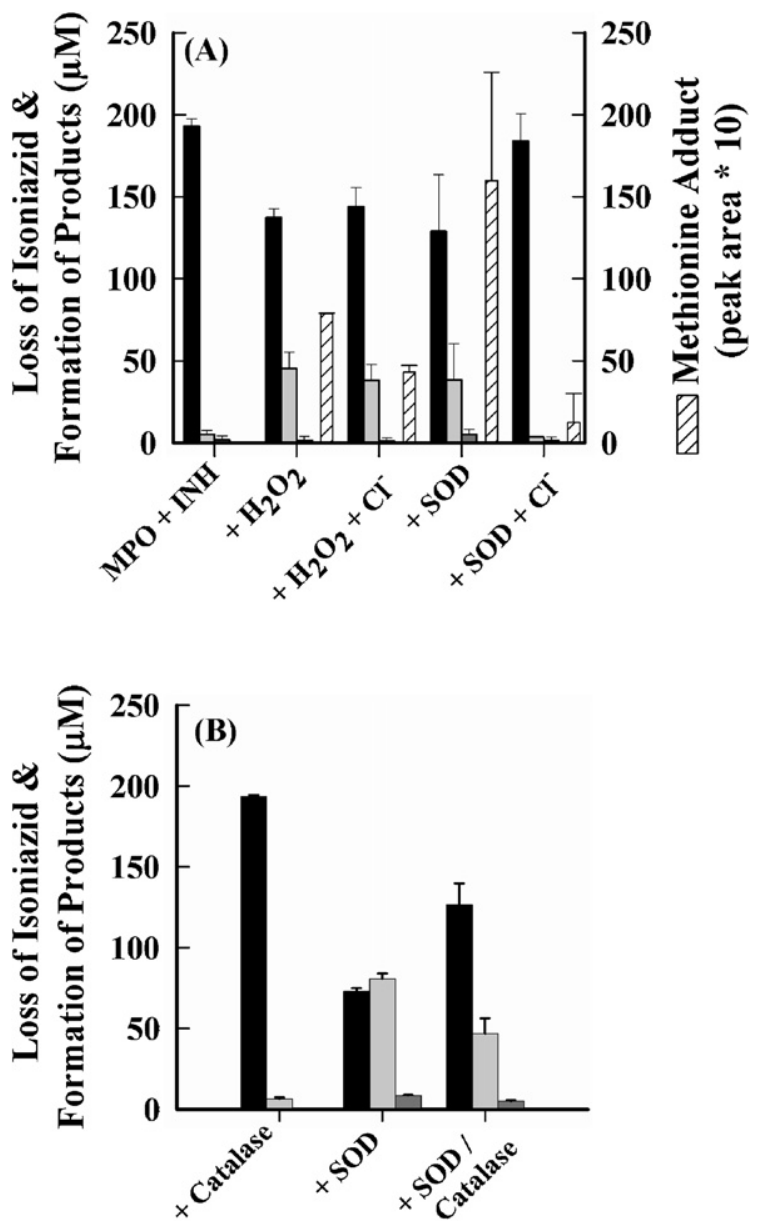

Fig. 5. The effect of chloride on isoniazid oxidation, and moderation of the SOD effect by catalase. (A) $200 \mathrm{nM}$ MPO was incubated with $200 \mu \mathrm{M}$ INH for $1 \mathrm{~h}$ at room temperature in $10 \mathrm{mM}$ phosphate buffer pH 7.4 containing $100 \mu \mathrm{M}$ DTPA, $1 \mathrm{mM}$ methionine, $\pm 140 \mathrm{mM} \mathrm{NaCl}$, with either $100 \mu \mathrm{M} \mathrm{H} \mathrm{H}_{2}$ or $40 \mu \mathrm{g} / \mathrm{mL}$ SOD. Reaction mixtures were analyzed by HPLC for INH (black bar), INA (light gray), INAM (dark gray) and Met.A (striped). Data presented are the means and ranges of duplicate experiments, and are representative of three experiments. (B) $200 \mathrm{nM}$ MPO and $200 \mu \mathrm{M}$ INH were incubated in $10 \mathrm{mM}$ phosphate buffer $\mathrm{pH} 7.4$ containing $100 \mu \mathrm{M}$ DTPA for $5 \mathrm{~h}$, with or without catalase $(20 \mu \mathrm{g} / \mathrm{mL})$ and SOD $(40 \mu \mathrm{g} / \mathrm{mL})$. Results shown are the means and ranges from two experiments, both carried out in the absence of methionine.

and hydrogen peroxide, MPO was captured on an ELISA plate and its activity as well as the amount of MPO was measured. The ratio of these two measurements was used to calculate the specific activity of MPO. INH had a modest effect on the specific activity of MPO with the greatest effect occurring at higher concentrations of hydrogen peroxide. At most there was only approximately $30 \%$ loss in specific activity (Fig. 9B). This was unaffected by the presence or absence of chloride in the incubation (not shown). Under the same conditions, however, ABAH completely inactivated MPO. These results show that there is some irreversible component to MPO inhibition by INH but this occurs only at high concentrations of hydrogen peroxide. Thus, the predominant mechanism is not that of an irreversible mechanism-based inhibitor.

\section{Discussion}

It is becoming increasingly apparent that neutrophils play a major role in host defense against $M t b$ [39]. This view is confirmed by the recent finding that neutrophils are the predominant infected phagocytic cell in the airways of patients with active pulmonary tuberculosis [6]. Elevated levels of MPO in pleural fluid [40] and serum of infected individuals [41] demonstrates that this 

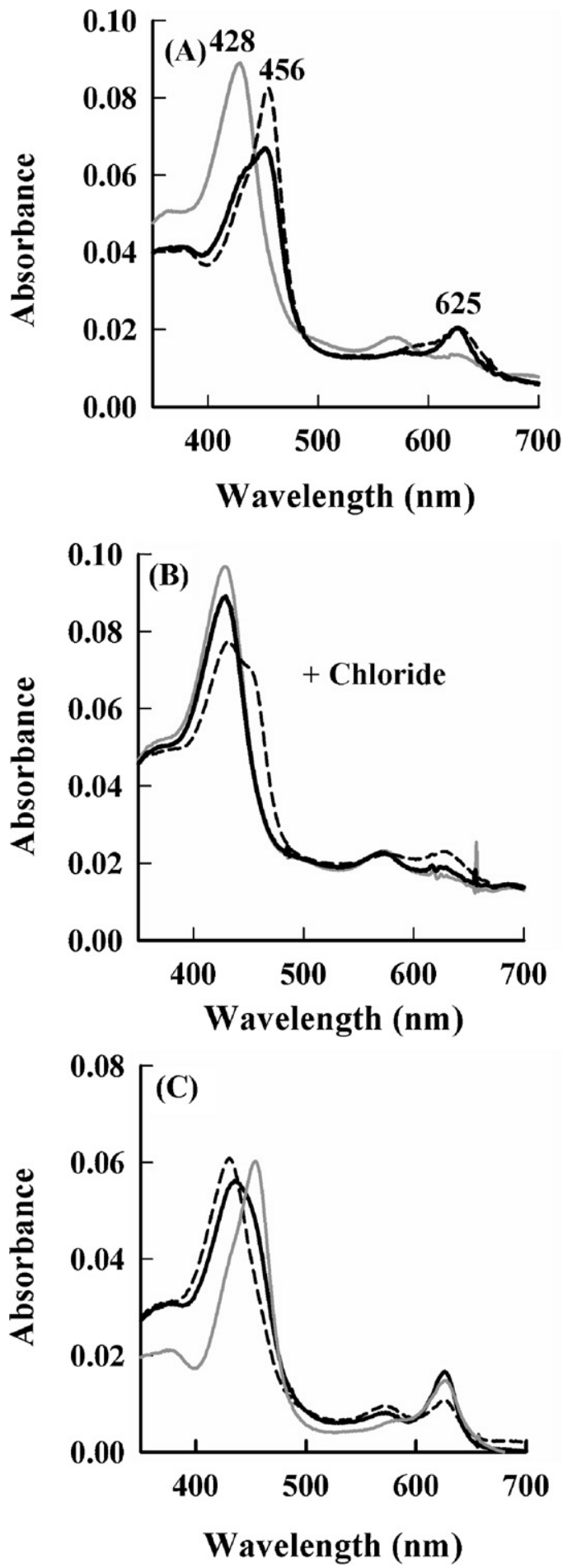

Fig. 6. Spectral changes of MPO during oxidation of INH. (A) Native ferric MPO $(1.2 \mu \mathrm{M})$ was incubated with INH $(10 \mu \mathrm{M})$ in $100 \mathrm{mM}$ phosphate buffer $\mathrm{pH} 7.4$ containing $1 \mathrm{mM}$ methionine (gray line). $\mathrm{H}_{2} \mathrm{O}_{2}(40 \mu \mathrm{M})$ was added and spectra were recorded after $15 \mathrm{~s}$ (dashed black line), and after $10 \mathrm{~min}$ (solid black line). (B) The same as (A) but with $140 \mathrm{mM} \mathrm{NaCl}$ in the buffer. (C) MPO $(1 \mu \mathrm{M})$ was converted to compound II (gray line) by adding $\mathrm{H}_{2} \mathrm{O}_{2}(167 \mu \mathrm{M})$ to the enzyme in $50 \mathrm{mM}$ phosphate buffer pH 7.4 containing $1 \mathrm{mM}$ methionine. Catalase $(20 \mu \mathrm{g} / \mathrm{mL})$ was then added to remove excess $\mathrm{H}_{2} \mathrm{O}_{2}$ and the spectrum was recorded 7 min later (dashed black line). This is compared to the same system with INH $(200 \mu \mathrm{M})$ added after the catalase, the spectrum recorded 1 min later (solid black line).

neutrophil-derived enzyme is relevant to the pathology and pharmacology of tuberculosis. Consequently, our new data on interactions between INH and MPO are pertinent to the effective treatment of patients with tuberculosis. We have shown that the
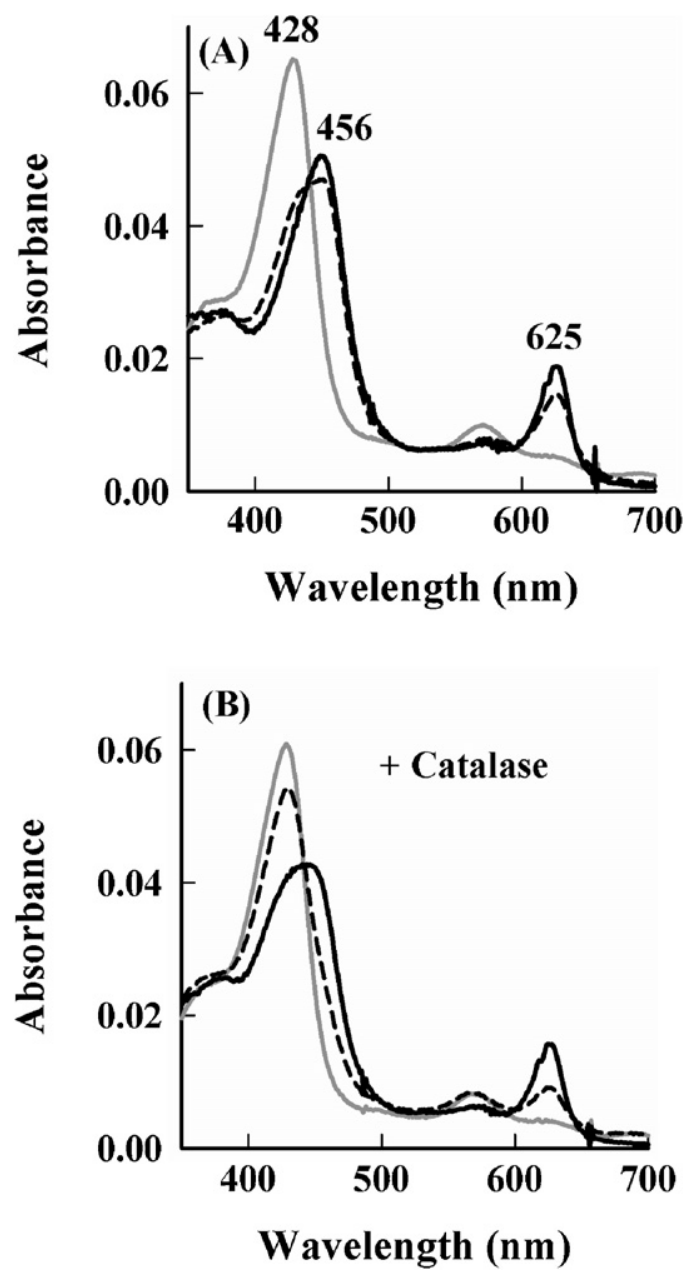

Fig. 7. Spectral changes of MPO in the presence of INH and SOD. MPO $(0.8 \mu \mathrm{M})$ was incubated in $50 \mathrm{mM}$ phosphate buffer $\mathrm{pH} 7.4$ containing $1 \mathrm{mM}$ methionine, in the absence (A) or presence (B) of $20 \mu \mathrm{g} / \mathrm{mL}$ catalase. After an initial spectrum was recorded (gray line), INH $(200 \mu \mathrm{M})$ and SOD $(40 \mu \mathrm{g} / \mathrm{mL})$ were added and spectra were recorded $1 \mathrm{~min}$ later (dashed black line). By $4 \mathrm{~min}$ stable spectra were recorded that remained unchanged up to 30 min later (solid black line).

reaction of INH with compound I of MPO is fast enough to ensure that it could occur at the sites of infection and inflammation. Oxidation of the drug by the enzyme is plausible because chloride, the physiological major substrate for MPO, had little influence on the hydrogen peroxide-dependent metabolism of INH. Our findings also demonstrate that once oxidized by MPO, INH will become conjugated to amine groups on proteins. These conjugates are potential haptens that may explain the autoimmune complications associated with extended treatment with INH. It is also apparent that interactions with INH will limit the ability of MPO to produce $\mathrm{HOCl}$, which may compromise host defense against Mtb. To fully appreciate how the interactions of INH and MPO will manifest in vivo, it is necessary to understand the mechanisms by which MPO oxidizes INH and the ultimate fate of the reactive species that are formed. The proposed mechanisms of oxidation of INH are outlined in Schemes 1 and 2.

We found that INH was a good substrate for compound I but reacted more slowly with compound II. The rate constant for reaction of compound I with INH has a similar value to those for physiological organic substrates such as urate, tyrosine, and ascorbate $[15,19,35]$. The reaction is also sufficiently fast to compete with oxidation of chloride [42] (see Scheme 1). The much larger rate constant for MPO compared to that for compound I of KatG $\left(4.3 \times 10^{4} \mathrm{M}^{-1} \mathrm{~s}^{-1}\right)$ most likely reflects the high reduction potential of the mammalian enzyme [16]. INH was a poor substrate 

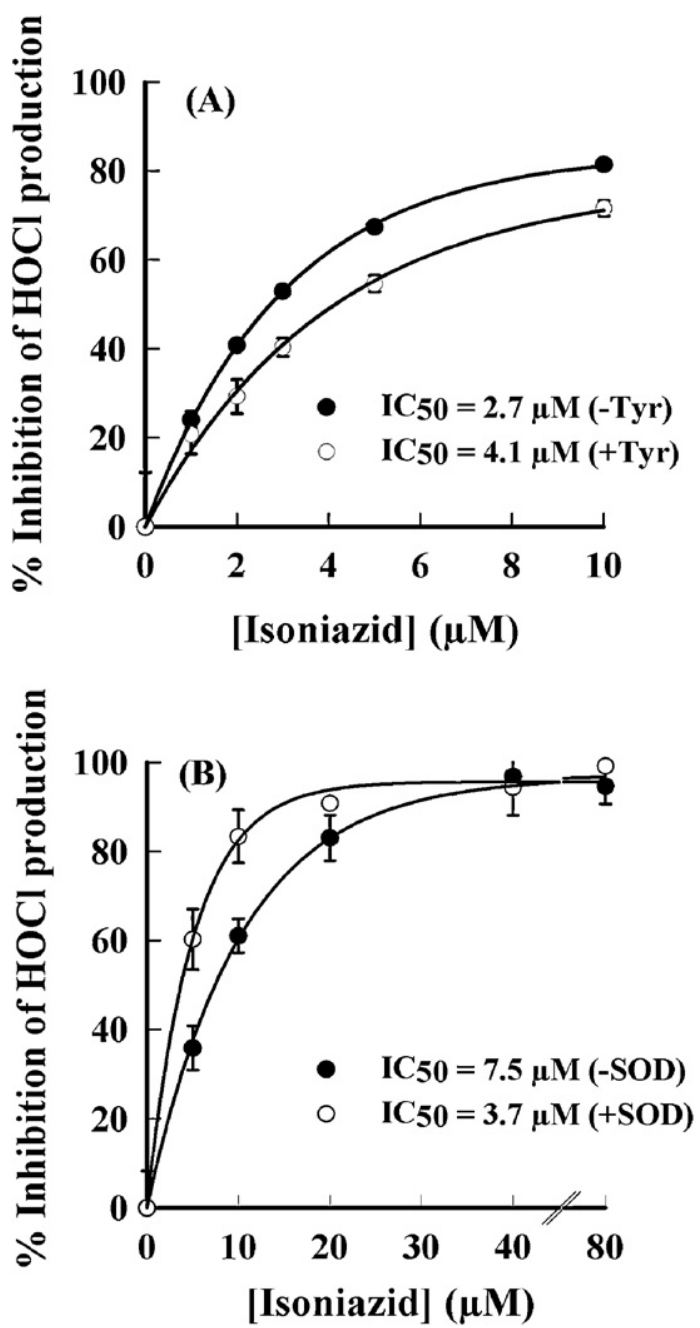

Fig. 8. Effect of INH on production of $\mathrm{HOCl}$ by purified MPO and isolated neutrophils (A) MPO $(20 \mathrm{nM})$ was incubated at room temperature with various concentrations of INH in PBS containing $5 \mathrm{mM}$ taurine. Reactions were started by adding $50 \mu \mathrm{M}$ $\mathrm{H}_{2} \mathrm{O}_{2}$ and stopped after $5 \mathrm{~min}$ with $20 \mu \mathrm{g} / \mathrm{mL}$ catalase, and were either in the presence (open circles) or absence (filled circles) of $10 \mu \mathrm{M}$ tyrosine. Data are means \pm SD representative of three experiments. (B) Neutrophils $\left(2 \times 10^{6} / \mathrm{mL}\right)$ were stimulated with PMA ( $100 \mathrm{ng} / \mathrm{mL}$ ) in Hanks buffer $\mathrm{pH} 7.4$, containing $5 \mathrm{mM}$ taurine and various concentrations of INH. Reactions were performed at $37^{\circ} \mathrm{C}$ in the presence (open circles) or absence (filled circles) of $40 \mu \mathrm{g} / \mathrm{mL}$ SOD and stopped after $20 \mathrm{~min}$ Cells $( \pm \mathrm{SOD})$ produced $22 \pm 1 \mu \mathrm{M} \mathrm{HOCl}$. Inhibition of $\mathrm{HOCl}$ production was determined relative to the control level measured in the absence of inhibitor. Data are means \pm SEM of duplicates, and are representative of three experiments.

for MPO compound II and reduced it about 10-fold slower than the physiological substrates for this redox intermediate. It is not immediately apparent why the reaction is slow because INH is a similar size to urate, ascorbate, and tyrosine, while the 1-electron oxidation to generate its radical (reduction potential of $\sim 500 \mathrm{mV}$ ) is similar to that of urate $(590 \mathrm{mV})$ and much less than that of tyrosine $(980 \mathrm{mV})[43,44]$. Hence, it would be expected to react at comparable rates to these substrates. With salicylhydroxamic acid, which is structurally related to INH, the aromatic ring binds to a hydrophobic region at the entrance to the distal heme pocket of MPO, while the hydroxamic acid moiety is hydrogen bonded to both the distal histidine 95 and the adjacent glutamine 91 amide group above the heme iron [45]. This orientation would be expected to favor oxidation. However, INH may react slowly because the orientation of the hydrazide moiety within the active site could be away from the heme group as occurs in lactoperoxidase [46]. The constrained active site of compound II may also
(A)

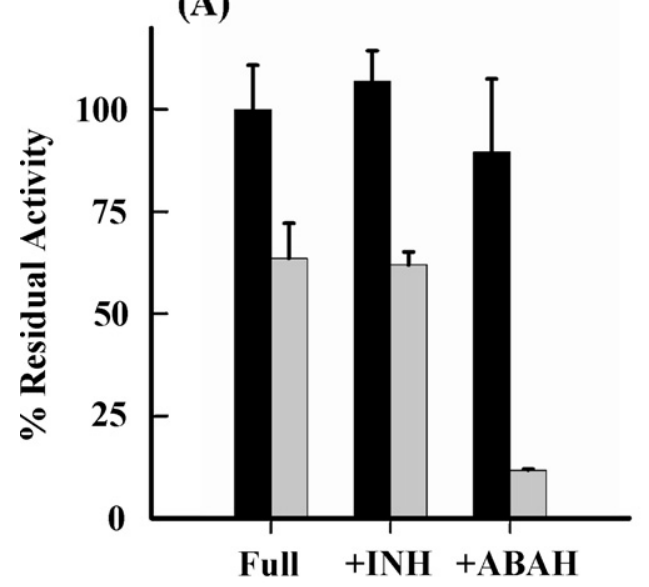

(B)

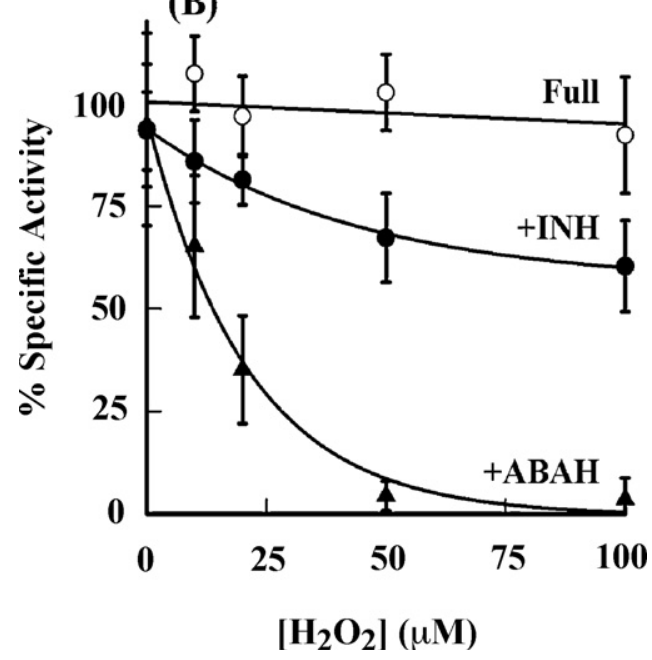

Fig. 9. Analysis of the reversibility of inhibition of MPO by INH. (A) MPO (150 nM) was incubated at room temperature in $10 \mathrm{mM}$ phosphate buffer $\mathrm{pH} 7.4$, containing $100 \mu \mathrm{M}$ DTPA, in the absence or presence of INH $(50 \mu \mathrm{M})$ or ABAH $(50 \mu \mathrm{M})$ as well as without (black bars) or with (gray bars) $\mathrm{H}_{2} \mathrm{O}_{2}(50 \mu \mathrm{M})$. Residual MPO activity was determined after $30 \mathrm{~min}$ and is relative to the control activity of MPO incubated without $\mathrm{H}_{2} \mathrm{O}_{2}$ or inhibitor. Mean values are plotted with SD error bars. (B) MPO $(100 \mathrm{nM})$ was incubated at room temperature in $100 \mathrm{mM}$ phosphate buffer $\mathrm{pH} 7.4$, containing $140 \mathrm{mM} \mathrm{NaCl}, 1 \mathrm{mM}$ methionine, $100 \mu \mathrm{M}$ DTPA, $\pm \mathrm{INH}(1 \mathrm{mM})$ or ABAH $(1 \mathrm{mM})$, with increasing concentrations of $\mathrm{H}_{2} \mathrm{O}_{2}$. Catalase $(20 \mu \mathrm{g} / \mathrm{mL})$ was added after $15 \mathrm{~min}$, then the specific activity was determined by ELISA. Specific activity is reported as the ratio of activity to the amount of protein, relative to that measured for MPO incubated without $\mathrm{H}_{2} \mathrm{O}_{2}$ or inhibitor. Data are means of duplicates \pm the sum of SD for the protein and activity measurements, and representative of two experiments.

restrict access of the hydrazide moiety [47]. Although comparatively slow, this reaction is much faster than the analogous reaction with compound II of $\operatorname{HRP}\left(\sim 40 \mathrm{M}^{-1} \mathrm{~s}^{-1}\right)$ [48].

Based on the measured rate constants, MPO will at least initially oxidize INH to the hydrazyl radical $(\bullet \mathrm{RH}$ in Schemes 1 and $\mathbf{2}$ in Scheme 2) via the classical peroxidation cycle (Scheme 1). However, in the stopped-flow experiments and steady-state spectral studies, it was apparent that compound II is eventually converted to compound III in a reaction that is independent of superoxide. Others have reported conversion of MPO and HRP to compound III during oxidation of INH [48-50]. Also, an analogous reaction occurs when MPO oxidizes $A B A H$, hydroquinone and melatonin $[33,34,51]$. We found that INH did not directly reduce ferric MPO and propose that the hydrazyl radical reduces the ferric enzyme because it is formed upon oxidation by compounds I and II. This reaction would produce ferrous MPO (Scheme 1) and implies that the hydrazyl radical is strongly reducing because the 


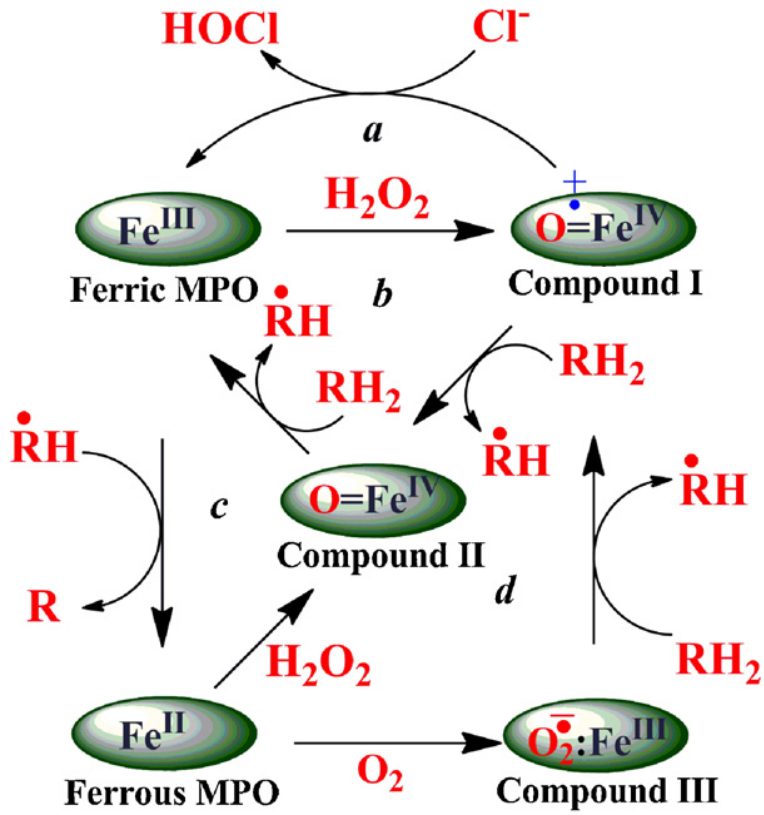

Scheme 1. Mechanism of oxidation of INH by MPO. The reaction scheme shows the redox transformations of MPO during the oxidation of isoniazid. The different redox cycles include $(a)$ chlorination, $(b)$ classical peroxidation, $(c)$ peroxidation involving ferrous MPO, and (d) peroxidation involving ferrous MPO and compound III. $\mathrm{RH}_{2}$ is isoniazid, ${ }^{\bullet} \mathrm{RH}$ is the hydrazyl radical, and $\mathrm{R}$ is the acyl diimide. For simplicity, only major products are shown.

reduction potentials for ferric MPO and ferric HRP are $24 \mathrm{mV}$ and $-278 \mathrm{mV}$, respectively. A similar reaction may occur with KatG because reported values for the reduction potential $[44,52,53]$ sit between those for these peroxidases.

Once formed, ferrous MPO binds molecular oxygen in an equilibrium reaction to form compound III $[17,18]$ or reacts with hydrogen peroxide to produce compound II [54]. Compound III would be formed at low concentrations of hydrogen peroxide, as observed in the SOD system. Compound III must turnover to sustain the oxidation of INH. In our reaction system, turnover would occur via reduction of compound III by INH to form compound I (Scheme 1). In support of this proposal, it has previously been shown that compound III is reduced by ascorbate [19], superoxide [20], and serotonin [21]. Compound III or oxyperoxidase of KatG is also reduced by INH [55]. The cycle with compound III would be fueled by molecular oxygen and produce super-stoichiometric concentrations of oxidized INH as observed with either SOD or addition of low concentrations of hydrogen peroxide. The cycle would be interrupted by chloride reacting with compound I, which would inhibit oxidation of INH as observed in the SOD system. At higher concentrations of hydrogen peroxide, ferrous MPO would be converted to compound II. Under these conditions a catalytic cycle involving ferric MPO, ferrous MPO as well as compounds I and II would be responsible for oxidizing INH (Scheme 1). The inability of hydrogen peroxide at higher concentrations to promote further oxidation of INH is explained by its capacity to inactivate the enzyme (see Fig. 9A) and react with compound I [56,57]. In addition to these mechanisms, good substrates for compounds I and II that produce oxidizing radicals, such as tyrosine, may also promote the oxidation of INH to the hydrazyl radical [48]. Thus, at sites of infection with Mtb, MPO is a credible candidate for the metabolism of INH and formation of hydrazyl radicals.

The fate of the hydrazyl radicals (2) is shown in Scheme 2 and will depend primarily on the local concentration of ascorbate and superoxide dismutase. Based on its reduction potential of approximately $0.5 \mathrm{~V}$ [44], the hydrazyl radical would be readily reduced by ascorbate ( $E^{\circ \prime}$ Asc $\bullet / A s c 0.28 \mathrm{~V}$ ) [43]. However, at low concentrations of ascorbate, as will occur at sites of inflammation where there is considerable oxidative stress, it will be free to react. It could break down to the acyl radical (4), or form the acyldiimide (3) either by disproportionation or reaction with molecular oxygen $[58,59]$. The acyl radical will react at diffusion controlled rates with oxygen to produce a peroxyl radical (5), which may foster a chain reaction by oxidizing another $\mathrm{INH}$ molecule and forming an acylhydroperoxide (6). Spin trapping experiments have previously established the existence of these radical species during peroxidase-mediated oxidation of INH [8]. The peroxyl radicals are highly oxidizing and in vivo they would promote free radical chain reactions such as lipid peroxidation.

Our finding that SOD promoted MPO-dependent oxidation of INH in the absence of added hydrogen peroxide illuminates the fate of the hydrazyl radicals. The effect of SOD is reminiscent of how it boosted the rate and stoichiometry of hydroquinone oxidation by MPO [34]. This was explained by the ability of SOD to shift the equilibrium for reduction of molecular oxygen by the semiquinone to the right simply by preventing the reverse reaction. In line with this chemistry, we propose that low concentrations of endogenous hydrogen peroxide present in the buffer are sufficient to initiate oxidation of INH by MPO to give the hydrazyl radical (2). It would not normally react with molecular oxygen because the equilibrium for this reaction would be strongly favored to the left as occurs with the analogous reactions of quinones with superoxide. In the presence of SOD, however, the equilibrium will be shifted to the right so that the acyl diimide (3) and hydrogen peroxide are produced. As long as molecular oxygen is available, the hydrogen peroxide formed by SOD would promote further oxidation of INH (Scheme 2).

We found that SOD also increased the proportion of oxidized INH that was conjugated to methionine. This is consistent with our mechanism if the resultant acyl diimide (3) undergoes nucleophilic attack by amines to form adducts (8). In support of this proposal, the acyl diimide of INH has been shown to undergo facile nucleophilic substitution reactions [60]. In the absence of SOD some of the hydrazyl radical must disproportionate to the acyl diimide (3) and form the adducts with methionine (8) as well as INA (7). In the presence of SOD, less of the hydrazyl radical (2) would breakdown to the acyl radical (4) while more would be converted to the acyl diimide (3). Consequently, the relative proportion of the methionine adduct $(\mathbf{8})$ to INA (7) would increase because the route leading to INA via the acyl radical (5) would be attenuated by SOD while that for the adduct would be enhanced.

The effect of SOD has important consequence for oxidation of INH in vivo. Mtb actively secretes an iron-containing superoxide dismutase (SODA) to inhibit the host responses to infections $[11,12]$. Hence sites of infection populated by neutrophils and Mtb will contain both MPO and SODA. Under these circumstances SODA will shift the hydrazyl radical formed by MPO toward the acyldiimide and subsequent conjugation to proteins. This is likely to spark the immune reactions of INH-induced lupus that have already been suspected to involve neutrophils and MPO. The potential for the radical intermediates of INH and the acylhydroperoxide to cause toxicity to host cells as well as Mtb also warrants consideration.

One of the new findings of our study is that INH is a good inhibitor of the chlorination activity of MPO and production of $\mathrm{HOCl}$ by neutrophils. The mechanism of inhibition involves competition between chloride and INH for oxidation by compound I with subsequent diversion of the enzyme along pathways involving compound II, ferrous MPO, and compound III that are outside the normal chlorination cycle (Scheme 1). Inhibition is not explained simply by the slow turnover of 


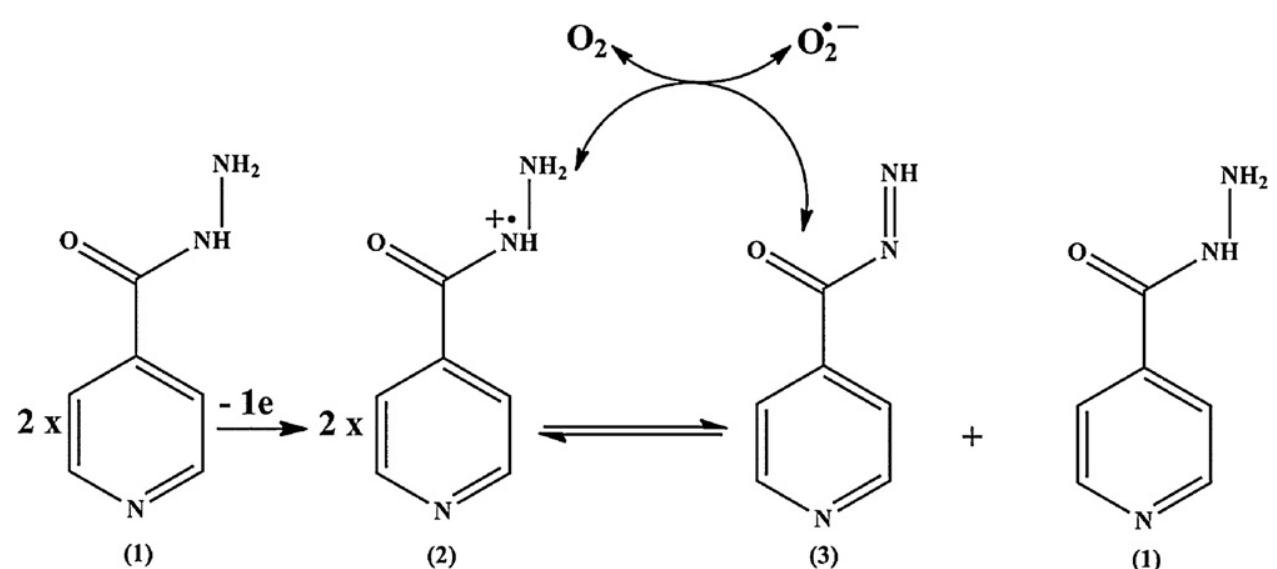

(1)

(2)<smiles>O=C(O)c1ccncc1</smiles>

(7)<smiles>O=C(O)c1ccncc1</smiles>

(6)

Scheme 2. Pathways for oxidation of INH by MPO. The different structures are (1) isoniazid, (2) hydrazyl radical, (3) acyl diimide, (4) acyl radical, (5) acyl peroxyl radical, (6) acyl hydroperoxide, (7) isonicotinic acid and (8) an acyl adduct with an amino acid. $\mathrm{RNH}_{2}$ is ammonia or an amino acid.

compound II because tyrosine and superoxide, which readily reduce this intermediate, could not effectively mitigate the loss in activity. The mechanism differs from those for ABAH [33] and 2-thioxanthines [61] because we found no evidence for irreversible enzyme inactivation. Inhibition occurred at concentrations well below the therapeutic dose so INH can be expected to inhibit production of $\mathrm{HOCl}$ at sites of $M t b$ infection. It should certainly inhibit production of $\mathrm{HOCl}$ by extracellular MPO. Whether or not it inhibits MPO within phagosomes and compromises host defense will depend on how readily it enters and accumulates within these compartments.

In summary, we have delineated the interactions between INH and MPO that will influence both the efficacy and adverse effects of this important drug. Exactly how these interactions manifest at sites of infection and whether they could be controlled will require further investigation. Demonstrating the conjugation of the acyl diimide to lysine residues in airway proteins from patients treated with INH will be a first step in this inquiry. Such data would provide the rationale for using ascorbate to scavenge INH radicals in an attempt to attenuate the adverse effects of INH.

\section{Acknowledgments}

We would like to thank the Health Research Council New Zealand and the Austrian Science Funds FWF (project P20664) for financial support.

\section{References}

[1] Egelund EF, Barth AB, Peloquin CA. Population pharmacokinetics and its role in anti-tuberculosis drug development and optimization of treatment. Curr Pharm Des 2011;17:2889-99.

[2] Riccardi G, Pasca MR, Buroni S. Mycobacterium tuberculosis: drug resistance and future perspectives. Future Microbiol 2009;4:597-614.

[3] Jenkins HE, Zignol M, Cohen T. Quantifying the burden and trends of isoniazid resistant tuberculosis, 1994-2009. PLoS One 2011;6.

[4] Rozwarski DA, Grant GA, Barton DHR, Jacobs WR, Sacchettini JC. Modification of the NADH of the isoniazid target (InhA) from Mycobacterium tuberculosis. Science 1998;279:98-102.

[5] Wiseman B, Carpena X, Feliz M, Donald LJ, Pons M, Fita I, et al. Isonicotinic acid hydrazide conversion to isonicotinyl-NAD by catalase-peroxidases. J Biol Chem 2010;285:26662-73.

[6] Eum S-Y, Kong J-H, Hong M-S, Lee Y-J, Kim J-H, Hwang S-H, et al. Neutrophils are the predominant infected phagocytic cells in the airways of patients with active pulmonary TB. Chest 2010;137:122-8 
[7] Hofstra AH, Limuller SMA, Uetrecht JP. Metabolism of isoniazid by activated leukocytes-possible role in drug-induced lupus. Drug Metab Dispos 1992;20:205-10.

[8] Goodwin DC, Aust SD, Grover TA. Free radicals produced during the oxidation of hydrazines by hypochlorous acid. Chem Res Toxicol 1996;9:1333-9.

[9] Winterbourn CC, Hampton MB, Livesey JH, Kettle AJ. Modeling the reactions of superoxide and myeloperoxidase in the neutrophil phagosome: implications for microbial killing. J Biol Chem 2006;281:39860-69.

[10] Jiang XX, Khursigara G, Rubin RL. Transformation of lupus-inducing drugs to cytotoxic products by activated neutrophils. Science 1994;266:810-3.

[11] Piddington DL, Fang FC, Laessig T, Cooper AM, Orme IM, Buchmeier NA. Cu,Zn superoxide dismutase of Mycobacterium tuberculosis contributes to survival in activated macrophages that are generating an oxidative burst. Infect Immun 2001;69:4980-7.

[12] Kusunose E, Ichihara K, Noda Y. Superoxide-dismutase from Mycobacterium tuberculosis. J Biochem 1976;80:1343-52.

[13] Kettle AJ, Winterbourn CC. Myeloperoxidase: a key regulator of neutrophil oxidant production. Redox Rep 1997;3:3-15.

[14] Arnhold J, Furtmüller PG, Regelsberger G, Obinger C. Redox properties of the couple compound I/native enzyme of myeloperoxidase and eosinophil peroxidase. Eur J Biochem 2001;268:5142-8.

[15] Meotti FC, Jameson GNL, Turner R, Harwood T, Stockwell S, Rees MD, et al. Urate as a physiological substrate for myeloperoxidase: implications for hyperuricemia and inflammation. J Biol Chem 2011;286:12901-11.

[16] Furtmüller PG, Arnhold J, Jantschko W, Pichler H, Obinger C. Redox properties of the couples compound I/compound II and compound II/native enzyme of human myeloperoxidase. Biochem Biophys Res Commun 2003;301:551-7.

[17] Abu-Soud HM, Raushel FM, Hazen SL. A novel multistep mechanism for oxygen binding to ferrous hemoproteins: rapid kinetic analysis of ferrousdioxy myeloperoxidase (compound III) formation. Biochemistry 2004;43:11589-95.

[18] Jantschko W, Furtmüller PG, Zederbauer M, Jakopitsch C, Obinger C. Kinetics of oxygen binding to ferrous myeloperoxidase. Arch Biochem Biophys 2004:426:91-7.

[19] Hsuanyu Y, Dunford HB. Oxidation of clozapine and ascorbate by myeloperoxidase. Arch Biochem Biophys 1999;368:413-20.

[20] Kettle AJ, Anderson RF, Hampton MB, Winterbourn CC. Reactions of superoxide with myeloperoxidase. Biochemistry 2007;46:4888-97.

[21] Ximenes VF, Maghzal GJ, Turner R, Kato Y, Winterbourn CC, Kettle AJ. Serotonin as a physiological substrate for myeloperoxidase and its superoxidedependent oxidation to cytotoxic tryptamine-4,5-dione. Biochem J 2010;425:285-93.

[22] Thee S, Detjen AA, Wahn U, Magdorf K. Isoniazid pharmacokinetic studies of the 1960: considering a higher isoniazid dose in childhood tuberculosis. Scand J Infect Dis 2010;42:294-8.

[23] Peloquin CA, Jaresko GS, Yong CL, Keung ACF, Bulpitt AE, Jelliffe RW. Population pharmacokinetic modeling of isoniazid, rifampin, and pyrazinamide. Antimicrob Agents Chemother 1997;41:2670-9.

[24] Conte JE, Golden JA, McQuitty M, Kipps J, Duncan S, McKenna E, et al. Effects of gender, AIDS, and acetylator status on intrapulmonary concentrations of isoniazid. Antimicrob Agents Chemother 2002;46:2358-64.

[25] Jiang X, Khursigara G, Rubin RL. Transformation of lupus-inducing drugs to cytotoxic products by activated neutrophils. Science 1994;266:810-3.

[26] Odajima T, Yamazaki I. Myeloperoxidase of the leukocytes of normal blood. I. Reaction of myeloperoxidase with hydrogen peroxide. Biochim Biophys Acta 1970;206:71-7.

[27] Beers RJ, Sizer IW. A spectrophotometric method for measuring the breakdown of hydrogen peroxide by catalase. J Biol Chem 1952;195:133-40.

[28] Dypbukt JM, Bishop C, Brooks WM, Thong B, Eriksson H, Kettle AJ. A sensitive and selective assay for chloramine production by myeloperoxidase. Free Radic Biol Med 2005;39:1468-77.

[29] Segal AW, Dorling J, Coade S. Kinetics of fusion of the cytoplasmic granules with phagocytic vacuoles in human polymorphonuclear leukocytes-biochemical and morphological-studies. J Cell Biol 1980;85:42-59.

[30] Mocatta TJ, Pilbrow AP, Cameron VA, Senthilmohan R, Frampton CM, Richards $\mathrm{AM}$, et al. Plasma concentrations of myeloperoxidase predict mortality after myocardial infarction. J Am Coll Cardiol 2007;49:1993-2000.

[31] Hoogland H, Vankuilenburg A, Vanriel C, Muijsers AO, Wever R. Spectral properties of myeloperoxidase compound-II and compound-III. Biochim Biophys Acta 1987;916:76-82.

[32] Winder FG, Denneny JM. Metal-catalysed auto-oxidation of isoniazid. Biochem J 1959:73:500-7.

[33] Kettle AJ, Gedye CA, Winterbourn CC. The mechanism of inactivation of myeloperoxidase by 4-aminobenzoic acid hydrazide. Biochem J 1997;321:503-8.

[34] Kettle AJ, Winterbourn CC. Oxidation of hydroquinone by myeloperoxidase: mechanism of stimulation by benzoquinone. J Biol Chem 1992;267:8319-24.

[35] Marquez LA, Dunford HB. Kinetics of oxidation of tyrosine and dityrosine by myeloperoxidase compounds I and II. Implications for lipoprotein peroxidation studies. J Biol Chem 1995;270:30434-40.
[36] Kettle AJ, Winterbourn CC. Mechanism of inhibition of myeloperoxidase by antiinflammatory drugs. Biochem Pharmacol 1991:41:1485-92.

[37] Jantschko W, Furtmüller PG, Zederbauer M, Neugschwandtner K, Lehner I, Jakopitsch C, et al. Exploitation of the unusual thermodynamic properties of human myeloperoxidase in inhibitor design. Biochem Pharmacol 2005;69:1149-57.

[38] Burner U, Obinger C, Paumann M, Furtmüller PG, Kettle AJ. Transient and steady-state kinetics of the oxidation of substituted benzoic acid hydrazides by myeloperoxidase. J Biol Chem 1999;274:9494-502.

[39] Mantovani A, Cassatella MA, Costantini C, Jaillon S. Neutrophils in the activation and regulation of innate and adaptive immunity. Nat Rev Immunol 2011;11:519-31.

[40] Segura RM, Alegre J, Varela E, Marti R, Surinach JM, Jufresa J, et al. Interleukin-8 and markers of neutrophil degranulation in pleural effusions. Am J Respir Crit Care Med 1998;157:1565-72.

[41] Koziol-Montewka M, Kolodziejek A, Oles J. Study on myeloperoxidase role in antituberculous defense in the context of cytokine activation. Inflammation 2004;28:53-8.

[42] Furtmüller PG, Burner U, Obinger C. Reaction of myeloperoxidase compound I with chloride, bromide, iodide, and thiocyanate. Biochemistry 1998;37: 17923-30.

[43] Buettner GR. The pecking order of free radicals and antioxidants: lipid peroxidation, $\alpha$-tocopherol, and ascorbate. Arch Biochem Biophys 1993;300:535-43.

[44] Wengenack NL, Lopes H, Kennedy MJ, Tavares P, Pereira AS, Moura I, et al Redox potential measurements of the Mycobacterium tuberculosis heme protein KatG and the isoniazid-resistant enzyme KatG(S315T): insights into isoniazid activation. Biochemistry 2000;39:11508-13.

[45] Davey CA, Fenna RE. 2.3 A resolution X-ray crystal structure of the bisubstrate analogue inhibitor salicylhydroxamic acid bound to human myeloperoxidase: a model for a prereaction complex with hydrogen peroxide. Biochemistry 1996;35:10967-73.

[46] Singh AK, Kumar RP, Pandey N, Singh N, Sinha M, Bhushan A, et al. Mode of binding of the tuberculosis prodrug isoniazid to heme peroxidases: binding studies and crystal structure of bovine lactoperoxidase with isoniazid at 2.7 angstrom resolution. J Biol Chem 2010;285:1569-76.

[47] Abu-Soud HM, Hazen SL. Interrogation of heme pocket environment of mammalian peroxidases with diatomic ligands. Biochemistry 2001;40:10747-55.

[48] Goodwin DC, Grover TA, Aust SD. Roles of efficient substrates in enhancement of peroxidase-catalyzed oxidations. Biochemistry 1997;36:139-47.

[49] van Zyl JM, Basson K, Uebel RA, van der Walt BJ. Isoniazid-mediated irreversible inhibition of the myeloperoxidase antimicrobial system of the human neutrophil and the effect of thyronines. Biochem Pharmacol 1989;38:2363-73.

[50] van der Walt BJ, van Zyl JM, Kriegler A. Aromatic hydroxylation during the myeloperoxidase-oxidase oxidation of hydrazines. Biochem Pharmacol 1994;47:1039-46.

[51] Ximenes VF, Silva Sde O, Rodrigues MR, Catalani LH, Maghzal GJ, Kettle AJ, et al. Superoxide-dependent oxidation of melatonin by myeloperoxidase. J Biol Chem 2005;280:38160-69.

[52] Zhang Z, Chouchane S, Magliozzo RS, Rusling JF. Direct voltammetry and catalysis with Mycobacterium tuberculosis catalase-peroxidase, peroxidases, and catalase in lipid films. Anal Chem 2002;74:163-70.

[53] Bellei M, Jakopitsch C, Battistuzzi G, Sola M, Obinger C. Redox thermodynamics of the ferric-ferrous couple of wild-type Synechocystis KatG and KatG(Y249F) Biochemistry 2006;45:4768-74

[54] Jantschko W, Furtmüller PG, Zederbauer M, Lanz M, Jakopitsch C, Obinger C. Direct conversion of ferrous myeloperoxidase to compound II by hydrogen peroxide: an anaerobic stopped-flow study. Biochem Biophys Res Commun 2003;312:292-8

[55] Ghiladi RA, Cabelli DE, de Montellano PRO. Superoxide reactivity of KatG: insights into isoniazid resistance pathways in TB. J Am Chem Soc 2004:126:4772-3.

[56] Furtmüller PG, Obinger C, Hsuanyu Y, Dunford HB. Mechanism of reaction of myeloperoxidase with hydrogen peroxide and chloride ion. Eur J Biochem 2000;267:5858-64.

[57] Kettle AJ, Winterbourn CC. A kinetic analysis of the catalase activity of myeloperoxidase. Biochemistry 2001;40:10204-12.

[58] Wengenack NL, Hoard HM, Rusnak F. Isoniazid oxidation by Mycobacterium tuberculosis KatG: a role for superoxide which correlates with isoniazid susceptibility. J Am Chem Soc 1999;121:9748-9.

[59] Amos RIJ, Gourlay BS, Schiesser CH, Smith JA, Yates BF. A mechanistic study on the oxidation of hydrazides: application to the tuberculosis drug isoniazid. Chem Commun 2008;1695-7.

[60] Amos RIJ, Schiesser CH, Smith JA, Yates BF. Nucleophilic acyl substitution of acyl diimides. J Org Chem 2009;74:5707-10.

[61] Tiden AK, Sjogren T, Svensson M, Bernlind A, Senthilmohan R, Auchere F, et al. 2-Thioxanthines are mechanism-based inactivators of myeloperoxidase that block oxidative stress during inflammation. J Biol Chem 2011;286: 37578-89. 